\title{
GREY RELATIONAL ANALYSIS BASED RANKING OF LATIN AMERICAN AND CARIBBEAN ECONOMIES
}

\section{DOI: 10.17261/Pressacademia.2015312957}

\author{
Bahadir Fatih Yildirim', Ali Hepsen², Emrah Onder ${ }^{3}$ \\ 'Istanbul University. bahadirfyildirim@gmail.com \\ ${ }^{2}$ Istanbul University. ailhepsen@yahoo.com \\ ${ }^{3}$ Istanbul University, emronder@gmail.com
}

\section{Keywords \\ Grey relational analysis, economic performance evaluation, Latin American and Caribbean Economies, macro-economic indicators.}

JEL Classification D00, E60, 012

\begin{abstract}
The countries of Latin America and Caribbean have had a modest performance in terms of economic growth since 2000. In addition, Latin America and the Caribbean has also been characterized as a region with a level of macroeconomic volatility much higher than developed economies. From this point of view, the aim of this study is to evaluate the economic performance of Latin American and Caribbean countries during 2003-2013 periods. 13 countries namely Argentina, Bolivia, Brazil, Chile, Colombia, Costa Rica, Dominican Republic, Ecuador, Mexico, Panama, Peru, Uruguay, Venezuela with highest GDP hold a position of importance in the Region. Grey Relational Analysis is used for the outranking of countries using macroeconomic indicators including total investment, gross national savings, inflation, average consumer prices, volume of imports of goods and services, volume of exports of goods and services, unemployment rate, general government revenue, general government total expenditure, general government gross debt, current account balance, gross product domestic (constant). Also annual macroeconomic indicators are converted to single data set by using arithmetic mean and weighted arithmetic mean (to be focused on recent years). This combined data was also used for another economic performance evaluation. The results of the empirical analyses show that Mexico and Dominican Republic ranked as first and second. The growth in these countries was robust, lifted by strengthening activity in the United States. In contrast, Argentina, Bolivia and Venezuela were at the bottom. These countries encountered difficulties maintaining sustained growth.
\end{abstract}

\section{INTRODUCTION}

The pace of Latin American economic growth will be the slowest in the past five years. According to forecasts, the region's economy will grow by 1-1.5\% in 2014 (compared with $2.5 \%$ in 2013 and $2.9 \%$ in 2012), before recovering slightly in 2015 to $2-2.5 \%$. Although growth levels vary from one country to another, partly because of different economic management strategies. Structural reforms must continue in order to boost potential output and equity. Productivity growth remains modest compared to that of the OECD 
countries and other emerging economies and, despite recent improvements, Latin America remains the world's most unequal region. Most significantly, commodity booms and short-term capital flow booms have not raised the region's growth potential.

As mentioned above, in 2013, the region grew by 2.5\%, down from 2.9\% growth in 2012 . This slowdown was due to lower export and lower domestic demand growth and some supply bottlenecks. Exports were hit by a downturn in global demand and commodity prices. Meanwhile, the slowdown in domestic demand was caused by the weakening of gross capital formation due to more pessimistic investor expectations and a loss of momentum for domestic credit. Private consumption continued to show solid growth, albeit at a slower pace due to the slight deterioration of labor market conditions and the slowdown in consumer credit. The region's economy is projected to grow by $1.2 \%$ according to Development Bank of Latin America and 1.1\% according to the Economic Commission for Latin America and the Caribbean (ECLAC) in 2014. Growth in 2014 will be hit by weak investment in most economies, modest US demand and the economic slowdown in China. Although the US recovery is expected to drive growth in exports over the next few quarters, Central America and Mexico could benefit more than South America, which will continue to be weighed down by the slowdown in Chinese demand and the decline of commodity prices. Nevertheless, the phase of the business cycle and growth prospects vary greatly from one country to another in the region. Peru and Chile, for instance, are experiencing a sharp economic slowdown due to deteriorating terms of trade and weaker investment. Estimates project a slight acceleration in the second half of 2014, but only to around 3\% for Peru and 2\% for Chile. Economic growth also slowed in Panama, due to weaker external demand, and is expected to reach only around $6 \%$ due to a slowdown in investment growth after major infrastructure projects have reached maturity. Growth in the Bolivia looks set to slip slightly to $5.5 \%$ after accelerating rapidly in 2013. It will continue to be underpinned by fuel exports to Brazil and Argentina and public investment. Brazilian growth has continued to slow and is unlikely to reach $0.5 \%$ in 2014 due to infrastructure bottlenecks and delays to pro-competitiveness reforms. According to projections, Uruguayan growth will slow to 3\% in 2014 and, as in Brazil, the economy will be affected by persistent inflationary pressures. Finally, the Argentinian and Venezuelan economies will contract in 2014 due to growing economic imbalances and double-digit inflation. The Colombian economy is recovering thanks to a monetary and fiscal stimulus and greater consumer optimism, and projections for 2014 predict growth of almost 5\%, enabling the output gap to close. In Mexico, fiscal stimuli and the US recovery are expected to lift growth to $2.5 \%$ in 2014 . Structural reforms recently passed, especially in energy, telecommunications, tax and education, could promote investment and raise growth potential in the coming years. Secondary legislation, which has not yet been drafted, will be vital to drive this process. Central American countries will also benefit from renewed demand from the US and additional tourism inflows. Costa Rica, Nicaragua and the Dominican Republic will grow by $4 \%$ to $4.5 \%$, and Guatemala and Honduras will grow at slightly lower rates of 3\% to $3.5 \%$. Finally, growth in the Caribbean economies is expected to accelerate from $1.2 \%$ in 2013 to $2 \%$ in 2014, bolstered by additional tourism thanks to the economic recovery in the United Kingdom and several countries in the euro 
area. In 2015, GDP growth is expected to rebound slightly in nearly all countries in the region, to around $2.5 \%$ on average. This growth will be supported by a recovery in global demand, thanks in particular to a shift to a more favorable phase of the business cycle in the United States and expansionary fiscal and monetary policies in countries that have the space to adopt them (Peru and Chile, for instance). The balance of risks for this outlook remains tilted to the downside, mainly by worsening external conditions. There is no perceived risk of adjustments to demand due to internal imbalances, except in a few South American economies. Nevertheless, the need for such adjustments would be precipitated by a further deterioration of external conditions.

\section{LITERATURE SURVEY}

In literature it was seen that multi criteria decision making techniques such as data envelope analysis, grey relational analysis, analytic hierarchy process, TOPSIS etc. are commonly used for ranking firms/countries regarding the financial/economic performance. Charnes, Cooper and Li (1989) studied the use of DEA (data envelopment analysis) as a tool for possible use in evaluating and planning the economic performance of China's cities (28 in all) which play a critical role in the government's program of economic development. They illustrated that DEA can be used to identify sources, and estimate amounts of inefficiencies in each city's performance. Zhu (1998) presented two alternative approaches to evaluate relative performance of decision making units which have multiple outputs and multiple inputs. These methods were data envelope analysis and principal component analysis. That employed to aggregate multiple performance measures for three real world data sets of Chinese cities. Zhu found that correlation between data envelope analysis and principal component analysis rankings is very high for each data set. Cherchye (2001) compared three DEA-based performance indicators of the OECD to illustrate how DEA models allow to estimate policy priorities. Huang and Jane (2009) combined the moving average autoregressive exogenous (ARX) prediction model with grey systems theory and rough set (RS) theory to create an automatic stock market forecasting and portfolio selection mechanism. Kung and Wen (2007) used six financial indicators to classify twenty items of financial ratios as research variables through the globalization Grey Relational Analysis (GRA), to find the significant financial ratio variables and other financial indicators affecting the financial performance of venture capital enterprises from 2001 to 2003 in Taiwan. They found that GRA is suitable for testing the relationship between attributes and financial performance of venture capital enterprises, and is the important method for investors to find out the more objective and successful investment target. Önder, Taş and Hepşen (2013) aimed to apply integrated ANP and TOPSIS to evaluate economic performance of Fragile 5 Countries in order to identify the fragility of them in economic recession period and beyond. Zhao, Kuo and Wang (2014) applied Grey Relational Analysis to rank and benchmark 9 tourist hotels in Taiwan by using 6 financial ratios-Current Ratio, Fixed assets turnover ratio, Debt Ratio, Return on Equity (ROE), Growth Rate of Operating Income and Account Receivable Turnover Ratio-as evaluation indicators. Hsieh et.al (2012) employed cluster grey relation analysis to induce macroeconomic performance evaluation model to in-depth discuss the potential of South 
Africa through the evaluation of ten economies. Hu and Li (2013) analyzed the factors affecting the price fluctuation of commercial housing in Harbin (China) from 2000 to 2010 using the grey relational analysis.

\section{MACROECONOMIC INDICATORS}

The aim of this study is to evaluate the economic performance of 13 Latin American and Caribbean countries (Argentina, Bolivia, Brazil, Chile, Colombia, Costa Rica, Dominican Republic, Ecuador, Mexico, Panama, Peru, Uruguay, Venezuela) during 2003-2013 period. Grey Relational Analysis is used for the outranking of those countries using macroeconomic indicators including total investment, gross national savings, inflation, average consumer prices, volume of imports of goods and services, volume of exports of goods and services, unemployment rate, general government revenue, general government total expenditure, general government gross debt, current account balance, gross product domestic (constant). The data related to indicators was gathered from the International Monetary Fund world economic outlook data base.

Gross Domestic Product represents the economic health of a country. It presents a sum of a country's production which consists of all purchases of goods and services produced by a country and services used by individuals, firms, foreigners and the governing bodies. GDP consists of consumer spending, investment expenditure, government spending and net exports hence it portrays an all-inclusive picture of an economy because of which it provides an insight to investors which highlights the trend of the economy by comparing GDP levels as an index. GDP is not only used as an indicator for most governments and economic decision-makers for planning and policy formulation; but also it helps the investors to manage their portfolios by providing them with guidance about the state of the economy. On the other hand, it is good measure for an economy and with improvement in research and quality of data, statisticians and governments are trying to find out measures to strengthen GDP and make it a comprehensive indicator of national income.

It is widely believed that there is a relationship between GDP and inflation. The problem is that there are disagreements as to what that relationship is or how it operates. As a result, when governments make decisions based on these pieces of information, the outcome often cannot be guaranteed. Exploration of the relationship between GDP and inflation is best begun by developing an understanding of each term individually. As mentioned above, GDP is an acronym for gross domestic product, which is the value of a nation's goods and services during a specified period. This figure is generally regarded as an important indicator of an economy's health. Inflation refers the rate at which the general level of prices for goods and services is rising, and, subsequently, purchasing power is falling.

International standards regarding the compilation of balance of payments statistics are described in the fifth edition of the Balance of Payments Manual prepared by the International Monetary Fund (IMF) in order to provide guidance to member countries. In a general sense, the balance of payments is a statistical statement that 
systematically records all the economic transactions between residents of a country (Central Government, monetary authority, banks, other sector) and nonresidents for a specific time period. The balance of payments statistics are classified under two major groups: "Current Account" and "Capital and Financial Account". In summary, the current account covers all transactions that involve real sources (including volume of exports and imports of goods and services,) and current transfers; the capital and financial accounts show how these transactions are financed (by means of capital transfer or investment in financial instruments). As mentioned in the European Economic series, current account deficits and surpluses are not necessarily macroeconomic imbalances in the sense of developments which are adversely affecting, or have the potential to affect the proper functioning of economies, of the monetary union, or on a wider scale. Deficits and surpluses are a natural consequence of economic interactions between countries. They show to which extent a country relies on borrowing from the rest of the world or how much of its resources it lends abroad. In this way, external borrowing and lending allows countries to trade consumption over time: a country with a current account surplus transfers consumption from today to tomorrow by investing abroad. In turn, a country with a current account deficit can increase its consumption or investment today but must transfer future income abroad to redeem its external debt. Deficits and surpluses can thus simply be the result of an appropriate allocation of savings, taking into account different investment opportunities across countries. Differences in economic prospects lead to differences in saving behavior, with brighter expectations reducing the tendency of economic agents to save and hence contributing to the accumulation of deficits. In particular, countries with a rapidly ageing population may find it opportune to save today to smooth consumption over time. On the other hand, current account deficits and surpluses are part of the adjustment process in a monetary union. They absorb asymmetric shocks in the absence of independent monetary policy and nominal exchange rate adjustment.

In determining the economic position of a country is through a comparison of population, national savings and total investments to the gross domestic product of the country. Finally, there is a negative relationship between changes in the rates of GDP growth and unemployment. This long-run relationship between the two economic variables was most famously pointed out in the early 1960s by economist Arthur Okun (known as Okun's Law). According to the principles established by this law, there is a corresponding two percent increase in employment (decrease in unemployment) for every established one percent increase in GDP. The reasoning behind this law is quite simple. It states that GDP levels are driven by the principles of demand and supply, and as such, an increase in demand leads to an increase in GDP. Such an increase in demand must be accompanied by a corresponding increase in productivity and employment to keep up with the demand.

\section{GREY RELATIONAL ANALYSIS}

Outranking and compare the alternatives with Grey Relational Analysis can best be treated under 6 steps (Wu 2002): 
- Preparing data set and construct decision matrix,

- Constructing reference series and compare matrix,

- Normalization process and constructing normalization matrix,

- Constructing absolute values table,

- Calculating the grey relational coefficient for each alternative,

- Calculating the grey relational degree.

Step 1. Preparing data set and construct decision matrix

Suppose there are $\mathrm{m}$ pieces of alternative, each alternative has $\mathrm{n}$ pieces of evaluating criteria. Sign the alternative as row subscript $i$, while sign the evaluating criterion as column subscript $\mathrm{j}$,

$$
\begin{array}{r}
x_{i}=\left(x_{i}(j), \ldots, x_{i}(n)\right), \quad \begin{array}{l}
i=1,2, \ldots, m \\
j
\end{array}=1,2, \ldots, n
\end{array}
$$

then build the initial decision matrix. $x i(j)$ is the entity in the ith data sequence corresponding to the jth criterion

$$
X=\left[\begin{array}{cccc}
x_{1}(1) & x_{1}(2) & \cdots & x_{1}(n) \\
x_{2}(1) & x_{2}(2) & \cdots & x_{2}(n) \\
\vdots & \vdots & \ddots & \vdots \\
x_{m}(1) & x_{m}(2) & \cdots & x_{m}(n)
\end{array}\right]
$$

Step 2. Constructing reference series and compare matrix

The reference series which uses for comparing alternatives is,

$$
x_{0}=\left(x_{0}(j), \ldots, x_{0}(n)\right) \quad j=1,2, \ldots, n
$$

Reference series get from the best indicator of alternative from normalization matrix. On Equation (3) $x_{0}(j)$ presents for beneficial indicator. Then, reference series add to decision matrix and transform to compare matrix.

Step 3. Normalization process and constructing normalization matrix

Because of using different scales and measure units in decision problem, we need to transform dataset to single scale for healthy comparing. Normalization process named as "grey relational generating" in some studies (Tsai et al. 2003).

Normalization process has 3 types belong to characteristic of the criteria 
Benefit attribute (the more the better): If bigger value effect the objective positively, Equation (4) uses for calculate normalization values.

$$
x_{i}^{*}=\frac{x_{i}(j)-\min _{j} x_{i}(j)}{\max _{j} x_{i}(j)-\min _{j} x_{i}(j)}
$$

Cost attribute (the less the better): If lower value effect the objective positively, Equation (5) uses for calculate normalization values.

$$
x_{i}^{*}=\frac{\max _{j} x_{i}(j)-x_{i}(j)}{\max _{j} x_{i}(j)-\min _{j} x_{i}(j)}
$$

Optimal attribute: If decision maker determine the optimal values, Equation (6) uses for calculate normalization values.

$$
x_{i}^{*}=\frac{\left|x_{i}(j)-x_{0 b}(j)\right|}{\max _{j} x_{i}(j)-x_{0 b}(j)}
$$

On Equation (6) $x_{0 b}(j)$ represent the optimal value, j. represent the target value of criteria and $x_{0 b}(j)$ within the range of $\max _{j} x_{i}(j) \geq x_{0 b}(j) \geq \min _{j} x_{i}(j)$.

After normalization process, the decision matrix transform to normalization matrix and symbolized with $X^{*}$.

$$
X^{*}=\left[\begin{array}{cccc}
x_{1}^{*}(1) & x_{1}^{*}(2) & \cdots & x_{1}^{*}(n) \\
x_{2}^{*}(1) & x_{2}^{*}(2) & \cdots & x_{2}^{*}(n) \\
\vdots & \vdots & \ddots & \vdots \\
x_{m}^{*}(1) & x_{m}^{*}(2) & \cdots & x_{m}^{*}(n)
\end{array}\right]
$$

Step 4. Constructing absolute values table

Absolute value between $x_{0}^{*}$ and $x_{i}^{*}$ present with $\Delta_{0 i}(j)$ and calculate with Equation (8).

$$
\begin{array}{r}
\Delta_{0 i}=\left|x_{0}^{*}(j)-x_{i}^{*}(j)\right| \quad \begin{array}{r}
i=1,2, \ldots, m \\
j=1,2, \ldots, n
\end{array}
\end{array}
$$




$$
\Delta_{0 i}=\left[\begin{array}{cccc}
\Delta_{01}(1) & \Delta_{01}(2) & \cdots & \Delta_{01}(n) \\
\Delta_{02}(1) & \Delta_{02}(1) & \cdots & \Delta_{02}(1) \\
\vdots & \vdots & \ddots & \vdots \\
\Delta_{0 m}(1) & \Delta_{0 m}(2) & \cdots & \Delta_{0 m}(n)
\end{array}\right]
$$

Step 5. Calculating the grey relational coefficient for each alternative

Grey relational coefficient matrix calculate with Equation (10).

$$
\begin{aligned}
& \gamma_{0 i}(j)=\frac{\Delta_{\min }+\zeta \Delta_{\max }}{\Delta_{0 i}(j)+\zeta \Delta_{\max }} \\
& \Delta_{\max }=\max _{i} \max _{j} \Delta_{0 i}(j) \\
& \Delta_{\min }=\min _{i} \min _{j} \Delta_{0 i}(j)
\end{aligned}
$$

On Equation (10) $\zeta$ parameter shows the distinguishing coefficient and represents the significance of. $\Delta_{\max }$, where $\zeta$ is $0 \leq \zeta \leq 1$ and smaller $\zeta$ is, the higher its distinguishability. Most studies in literature $\zeta=0,5$ because of offering moderate distinguishing effects and good stability (Baş 2010).

Step 6. Calculating the grey relational degree

On a grey system, grey relational degree represents the geometric similarity between $x_{i}^{*}$ and $x_{0}^{*}$ reference series and provide to compare the series. Bigger grey relational degree shows stronger relation between $x_{i}^{*}$ and $x_{0}^{*}$ reference series. When grey relational degree equal to 1, we can say compared series are same (Yılmaz and Güngör 2010).

Grey relational degree calculate with different ways belong to priority weight for criteria.

$$
\Gamma_{0 i}=\frac{1}{n} \sum_{j=1}^{n} \gamma_{0 i}(j)
$$

If criteria have equal priority weights, Equation (12) use for calculate. If criteria have different priority weights (w), Equation (13) use for calculating the grey relational degree

$$
\Gamma_{0 i}=\sum_{j=1}^{n}\left[w_{i}(j) \cdot \gamma_{0 i}(j)\right]
$$

$\mathrm{w}_{\mathrm{j}}$ represent the priority weight of the $\mathrm{j}^{\text {th }}$ criterion. 


\section{APPLICATION}

In this paper Grey Relation Analysis used for ranking the financial performance of Latin American and Caribbean economies.

\subsection{Data}

In this paper purposed macroeconomic indicators including total investment, gross national savings, inflation, average consumer prices, volume of imports of goods and services, volume of exports of goods and services, unemployment rate, general government revenue, general government total expenditure, general government gross debt, current account balance, gross product domestic (constant). This macroeconomic indicators used as criteria of decision problem. Data collected from World Economic Outlook Database, October 2014 edition which published by International Monetary Fund (IMF). Data set contains 2003-2013 periods. Latin American and Caribbean country group hosts 36 countries but in this paper we choose countries with highest GDP hold a position of importance in the Latin American and Caribbean region. This countries are Argentina, Bolivia, Brazil, Chile, Colombia, Costa Rica, Dominican Republic, Ecuador, Mexico, Panama, Peru, Uruguay, and Venezuela.

\subsection{Weight Determined}

In this study, criteria priority weights taken from Önder et al. (2015)'s paper. In that paper, researchers used Analytical Network Process (ANP) to determine the weights of macroeconomic indicators. According to expert's judgments based ANP analysis, "Gross domestic product, constant prices" (0.2567) was the most important macroeconomic indicator influencing countries' economies followed by "Current account balance" (0.1936) and "Inflation, average consumer prices" (0.1490). The least important priorities are "Gross national savings" (0.0145) and "General government revenue" (0.0185). Resulting weights obtained with expert judgments based ANP are shown on Figure 1. 


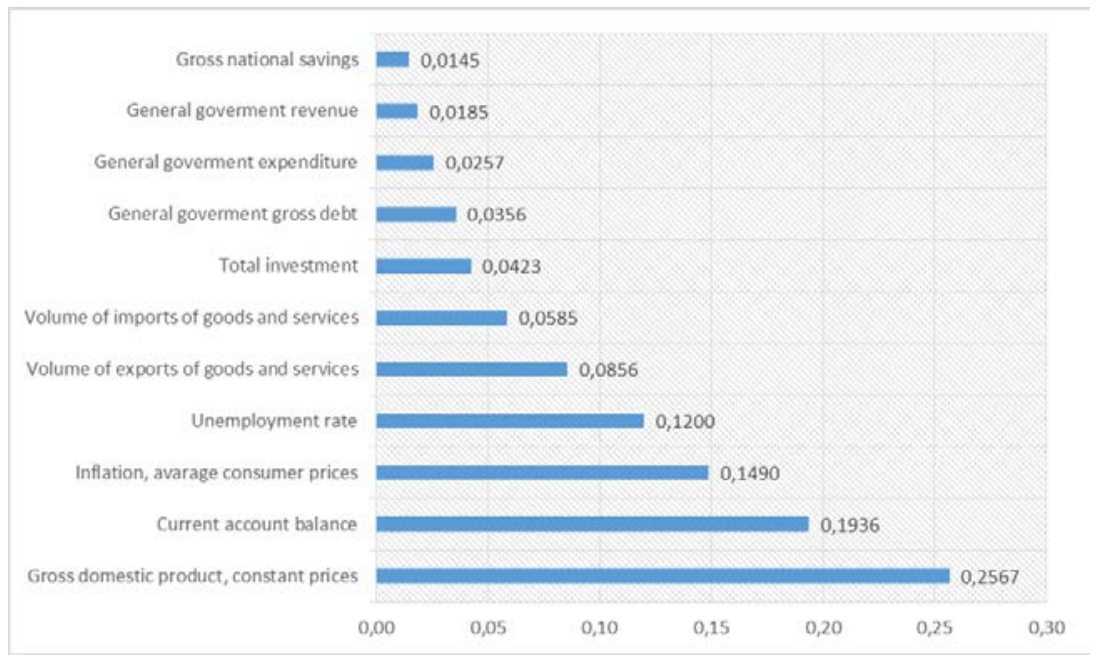

Figure 1. Weights obtained with expert judgments based ANP (Önder et. al., 2015)

\subsection{Ranking on Financial Performance of Latin American and Caribbean Economies}

The proposed model of this paper uses a combined method. Calculated Analytical Network Process (ANP) based weights, implant to Grey Relational Analysis for ranking 13 Latin American and Caribbean economies depends on their macroeconomic indicators 2003-2013 periods. Also annual period macroeconomic indicators are converted to single data set by using arithmetic mean and weighted arithmetic mean (to be focused on recent years). This combined data was also used for another economic performance evaluation. By using GRA method, the ranking of countries are calculated and shown on Table 1.

Table 1: Ranking of Countries by Using GRA

\begin{tabular}{|c|c|c|c|c|c|c|c|c|c|c|c|c|c|}
\hline & $\stackrel{m}{\stackrel{\nu}{0}}$ & ঠ্ঠ & 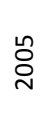 & ஜ̊ & ঠ̊ & $\stackrel{\infty}{\stackrel{\nu}{~}}$ & ஓ્̀ & 옹 & $\underset{\sim}{\stackrel{ }{\sim}}$ & $\underset{\sim}{\stackrel{\sim}{0}}$ & $\stackrel{m}{\stackrel{n}{\sigma}}$ & $\begin{array}{l}\frac{c}{\pi} \\
\stackrel{\mathbb{O}}{\Sigma} \\
\dot{4}\end{array}$ & 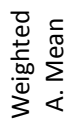 \\
\hline Argentina & 3 & 12 & 12 & 12 & 12 & 8 & 4 & 1 & 11 & 12 & 12 & 11 & 11 \\
\hline Bolivia & 6 & 6 & 5 & 5 & 7 & 13 & 12 & 5 & 10 & 11 & 11 & 10 & 12 \\
\hline Brazil & 11 & 11 & 2 & 2 & 8 & 5 & 5 & 13 & 1 & 1 & 1 & 2 & 3 \\
\hline Chile & 8 & 8 & 10 & 7 & 5 & 4 & 8 & 12 & 6 & 4 & 4 & 6 & 6 \\
\hline Colombia & 10 & 7 & 7 & 10 & 11 & 6 & 13 & 6 & 12 & 7 & 7 & 9 & 7 \\
\hline
\end{tabular}




\begin{tabular}{lccccccccccccc} 
Costa Rica & 5 & 3 & 9 & 9 & 4 & 3 & 3 & 10 & 4 & 10 & 10 & 5 & 5 \\
Dominican Republic & 13 & 4 & 3 & 11 & 3 & 2 & 2 & 3 & 3 & 2 & 2 & 4 & 2 \\
Ecuador & 9 & 9 & 6 & 4 & 2 & 11 & 9 & 8 & 7 & 9 & 9 & 7 & 8 \\
Mexico & 2 & 2 & 1 & 1 & 1 & 1 & 1 & 7 & 2 & 3 & 3 & 1 & 1 \\
Panama & 1 & 1 & 4 & 6 & 6 & 7 & 10 & 2 & 5 & 5 & 5 & 3 & 4 \\
Peru & 7 & 5 & 8 & 8 & 9 & 10 & 7 & 9 & 9 & 8 & 8 & 8 & 9 \\
Uruguay & 12 & 10 & 11 & 3 & 10 & 9 & 11 & 11 & 8 & 6 & 6 & 12 & 10 \\
Venezuela & 4 & 13 & 13 & 13 & 13 & 12 & 6 & 4 & 13 & 13 & 13 & 13 & 13 \\
\hline
\end{tabular}

\section{CONCLUSION}

The countries of Latin America and Caribbean have had a modest performance in terms of economic growth since 2000. Latin America and the Caribbean has also been characterized as a region with a level of macroeconomic volatility much higher than developed economies. From this point of view, the aim of this study is to evaluate the economic performance of Latin American and Caribbean countries. 13 countries namely Argentina, Bolivia, Brazil, Chile, Colombia, Costa Rica, Dominican Republic, Ecuador, Mexico, Panama, Peru, Uruguay, Venezuela with highest GDP hold a position of importance in the Region. Grey Relational Analysis is used for the outranking of countries using macroeconomic indicators. Also annual macroeconomic indicators are converted to single data set by using arithmetic mean and weighted arithmetic mean. This combined data was also used for another economic performance evaluation.

According to our Grey Relational Analysis method (weighted arithmetic mean), Argentina, Bolivia, Uruguay and Venezuela were at the bottom during 2003-2013 period. Looking beyond, not surprisingly, drop in oil prices has important effects on these countries. For example, each $\$ 10$ decline in oil prices worsens Venezuela's trade balance by $3 \frac{1}{2}$ percent of GDP, a bigger effect by far than for any other country in the region. The loss in export revenue causes mounting fiscal problems and a sharper economic downturn. In addition to lower oil prices, political uncertainty and greater global risk aversion are also dampening growth prospects for Bolivia, Colombia and Ecuador. In all three countries, fiscal balances have suffered from falling oil revenue.

On the other hand, our model shows that although Brazil has the most fragile economy after great recession period (in the year 2010), but afterwards the performance of Brazil economy is relatively high and ranked first in the year 2013 due to Chinese demand for commodities.

The results of the empirical analyses emphasizes that Mexico and Dominican Republic ranked as first and second in terms of the weighted arithmetic mean. The growth in these countries was robust, lifted by strengthening activity in the United States. 
The findings of this paper would help governments for taking necessary precautions and foreign investors for creating more effective investment strategies.

\section{Acknowledgment}

This study was supported financially by Istanbul University (BAP-UDP Project no: 51744).

\section{REFERENCES}

Baş, M. (2010) İşletmelerde Finansal Başarısızlığın Öngörülmesinde Gri İlişkisel Analiz Tekniği, Tekstil ve Deri Sektöründe Bir Uygulama. Dissertation, Dumlupınar University.

Charnes, A., Cooper, W.W., Li, S. (1989) Using data envelopment analysis to evaluate efficiency in the economic performance of Chinese cities. Socio-Economic Planning Sciences, 23, 6:325-344.

Cherchye, L., (2001) Using data envelopment analysis to assess macroeconomic policy performance. Applied Economics, 2001, 33:407-416.

Hsieh, M.Y., Huang, C.H., Kung, C.Y., Wu, W.M. (2012) Employing the Multiple Criteria Decision Making methodology to in-depth discuss the potential of South Africa through the evaluation of ten economies. Proceedings of the 2012 International Conference on Machine Learning and Cybernetics, Xian, 15-17 July, 2012.

Hu, Y., Li, P. (2013) A Grey Relational Analysis on Factors Affecting the Price of Commercial Housing. Proceedings ICCREM 2013, doi: 10.1061/9780784413135.088, 929-936.

Huang, K.Y., Jane, C.J. (2009) A hybrid model for stock market forecasting and portfolio selection based on ARX, grey system and RS theories. Expert Systems with Applications 36:5387-5392

IMF, (2014) World Economic Outlook Database: October 2014 Edition. http://www.imf.org/external/pubs/ft/weo/2014/02/weodata/index.aspx, Accessed 17 March 2015

Kung, C.Y., Wen, K.L., 820079 Applying Grey Relational Analysis and Grey Decision-Making to evaluate the relationship between company attributes and its financial performance: A case study of venture capital enterprises in Taiwan. Decision Support Systems 43: 842-852

OECD, (2014) Latin American Economic Outlook 2015. Accessed 20 March 2015.

Önder E., Taş N., Hepşen A. (2014) Economic Performance Evaluation Of Fragile 5 Countries After The Great Recession Of 2008-2009 Using Analytic Network Process And TOPSIS Methods. Journal of Applied Finance and Banking (JAFB), 5, 1:1-17.

Tsai, C.H., Chang, C.L. ve Chen, L. (2003) Applying Grey Relational Analysis to The Vendor Evaluation Model. International Journal of The Computer. The Internet and Management, 11, 3:45-53.

Wu, H. H. (2002) A Comparative Study of Using Grey Relational Analysis in Multiple Attribute Decision Making Problems. Quality Engineering, 159, 2:209-217.

Yılmaz, E. ve Güngör, F., (2010) Gri İlişkisel Analiz Yöntemine Göre Farklı Sertliklerde Optimum Takım Tutucusunun Belirlenmesi. 2. Ulusal Tasarım İmalat ve Analiz Kongresi, 11-12 November 2010, Balıkesir, 1-9.

Zhao, D., Kuo, S.H., Wang, T.C. (2014) The Evaluation of the Business Operation Performance by Applying Grey Relational Analysis, Advances in Intelligent Systems and Computing, 297:441-450.

Zhu, J., (1998) Data envelopment analysis vs. principal component analysis: An illustrative study of economic performance of Chinese cities. European Journal of Operational Research, 1, 1:50-61 